\title{
\#STAYHOME: MONITORING SOCIAL DISTANCING TRENDS IN AMAZONAS DURING THE COVID-19 PANDEMIC USING GOOGLE MOBILE DATA
}

\author{
Patricia Endo ${ }^{1}$, Gisliany Lillian Alves de Oliveira ${ }^{2}$, Luciana Conceição de Lima $^{2}$, Ivanovitch Silva ${ }^{2}$, \\ Guto Leoni ${ }^{3}$ and Theo Lynn ${ }^{4}$ \\ ${ }^{1}$ Universidade de Pernambuco, Recife, Brazil \\ ${ }^{2}$ Universidade Federal do Rio Grande do Norte, Natal, Brazil \\ ${ }^{3}$ Centro de Informática, Universidade Federal de Pernambuco, Recife, Brazil \\ ${ }^{4}$ Irish Institute for Digital Business, DCU Business School, Dublin, Ireland
}

\begin{abstract}
Controlling COVID-19 poses significant disease control challenges due to its contagiousness and uncertain infectivity of asymptomatic and clinically mild cases. Uninfected and silent carriers contributed significantly to the spread of the disease. For most of 2020, no strain-specific control options were available and consequently non-pharmaceutical intervention strategies were typically used by Governments worldwide for disease control. The COVID-19 pandemic is the first time that the social, mobile, cloud, and big data technologies could be exploited en masse to inform decision making on a local and global scale. This paper examines the public response to policies adopted by the State of Amazonas in Brazil using Google Mobile Community Report data. Our analysis suggests that while public did response to government public health interventions, there is clear evidence of a decline in adherence from April onwards resulting in a further spike in cases and deaths in September. The analysis suggests that mobile data is a useful and low-cost proxy for social distancing adherence that can help to inform both regional and local public health interventions. It also suggests that policymakers must consider measures to counter declines in adherence when designing such policies, and consider what actions can be taken to encourage access, adoption and use of mobile data for public health surveillance while addressing concerns about data privacy and data protection.
\end{abstract}

\section{KEYWORDS}

COVID-19, Coronavirus Pandemic, Google Mobile Data, Social Distancing, Health Surveillance

\section{INTRODUCTION}

The contagiousness of COVID-19 combined with uncertain infectivity of asymptomatic and clinically mild cases, poses significant challenges in controlling the disease. The daily movements of the uninfected and silent carriers can inadvertently spread the disease. In the absence of strain-specific control options, non-pharmaceutical public health intervention strategies have been rolled out by governments worldwide to mitigate the spread and associated impact of the virus. Social distancing includes bans on public gatherings, education and non-essential business closures, transport and travel restrictions, and self-isolation measures. In addition to direct effects on disease control, such measures can reduce the pressure on health systems. Against this backdrop, public health decision makers not only require timely data on infections and mortality, but human behavior, and specifically, mobility and the co-presence of people (Oliver et al. 2020).

The COVID-19 pandemic is the first time that the 'third IT platform', comprising social, mobile, cloud, and big data technologies, can be exploited to inform decision making on a local and global scale. However, data incompleteness, availability, and privacy concerns impact such health surveillance (Tizzoni et al. 2014). Public-private collaborations worldwide are using mobile data to contribute to situational awareness, understanding causality, predictive modeling and impact assessment for COVID-19 (Oliver et al. 2020). Due to the ubiquity, personal nature, and passive connectivity of mobile phones, mobile data is particularly useful as a proxy for individual mobility (Tizzoni et al. 2014). 
While authorities collect and model data on reported cases and deaths, data on the effectiveness of interventions, such as social distancing, is lacking. As discussed, anonymous mobile phone traces can be used as a proxy of human movement and social interactions in the absence of mobility data from official sources (Oliver et al. 2020; Tizzoni et al. 2014). In previous influenza epidemics, daily mobility has been linked to regional spread of infectious disease (Charaudeau et al. 2014). By understanding daily mobility trends, it is possible to infer the efficacy of social distancing and other related public health interventions.

At the time of writing, Brazil had the third largest incidences of COVID-19 cases and second largest incidences of COVID-19 deaths in the world (CSSE, 2020). In this paper, we explore the utility of Google Community Mobility Report data for evaluating the efficacy of social distancing and related public health interventions in the largest state in Brazil, Amazonas. We construct a social distancing indicator as per de Oliveira et al. (2020) based in Google Mobile Community Report data and explore how insightful this data is against the backdrop of known government policy responses and intervention.

\section{EMPIRICAL CONTEXT}

Amazonas is the largest state in Brazil, covered almost entirely by the Amazon rainforest. It has over 4 million inhabitants, over half of which reside in Manaus. From a public health perspective, Amazonas has unique challenges resulting from a combination of environmental, climate and socio-economic factors that make the region a hotspot for a wide range of endemic diseases including tuberculosis, malaria and arboviruses. On 16 March 2020, the State Government of Amazonas declared a public health emergency and associated measures to mitigate the spread of COVID-19 including suspension of education, cancelling state events, and restricting travel by public servants, but crucially did not include quarantine or social isolation (FVS, 2020). A declaration of a wider state of catastrophe followed on 23 March allowing the use of further exceptional measures in the fight against COVID-19 (FVS, 2020). By early April, intercity and interstate land transportation, and river passenger services were suspended, except for those returning home, and the use of masks and alcohol gels was mandatory (FVS, 2020). Despite these measures, COVID-19 is badly affecting Amazonas. By 4 April, there were 7,313 confirmed cases of COVID-19 and 585 deaths (FVS, 2020). By mid-April, authorities in Manaus were reporting over 100 COVID-19 deaths per day with insufficient capacity in the Sistema Único de Saúde (SUS), the Brazilian public health system, and cemeteries to deal with the impact of the pandemic (G1, 2020). Enforcing social distancing is particularly challenging due to the climate and socio-economic conditions and behaviors. Indigenous populations, the poor, and those with compromised immune and respiratory systems (often from other endemic diseases), are particularly at risk. There was an intense COVID-19 outbreak in the Northern Region of Brazil starting in mid-April that adversely impacted the states of Amazonas, Pará, Ceará and Pernambuco. In Manaus, the capital and largest city in Amazonas had a 4.5 fold excess morality by early May; by June, $44 \%$ of the population in Manaus had detectable COVID-19 antibodies (Orellana et al. 2020; Buss et al. 2020). After a re-emphasis on social distancing during the summer months by the State Government, the re-opening of schools introduced further uncertainty on the need to adhere to social distancing and the associated impact. By October 2020, the COVID-19 attack rate in Manaus rose to $76 \%$, above the theoretical herd immunity threshold of $70 \%$ however research also suggest significant antibody waning suggests that the public may be subject to iterative waves of infection (Buss et al. 2020).

\section{ANALYSIS}

Google Community Mobility Reports provide aggregated anonymized daily spatio-temporal data on movement trends, across different place categories (e.g. recreation \& retail, grocery \& pharmacy, parks, transit stations, workplaces, and residential). Google collate the data from users who have given permission to share their Location History setting, which is off by default. In this paper, data was used from 14 February to 10 December 2020. 

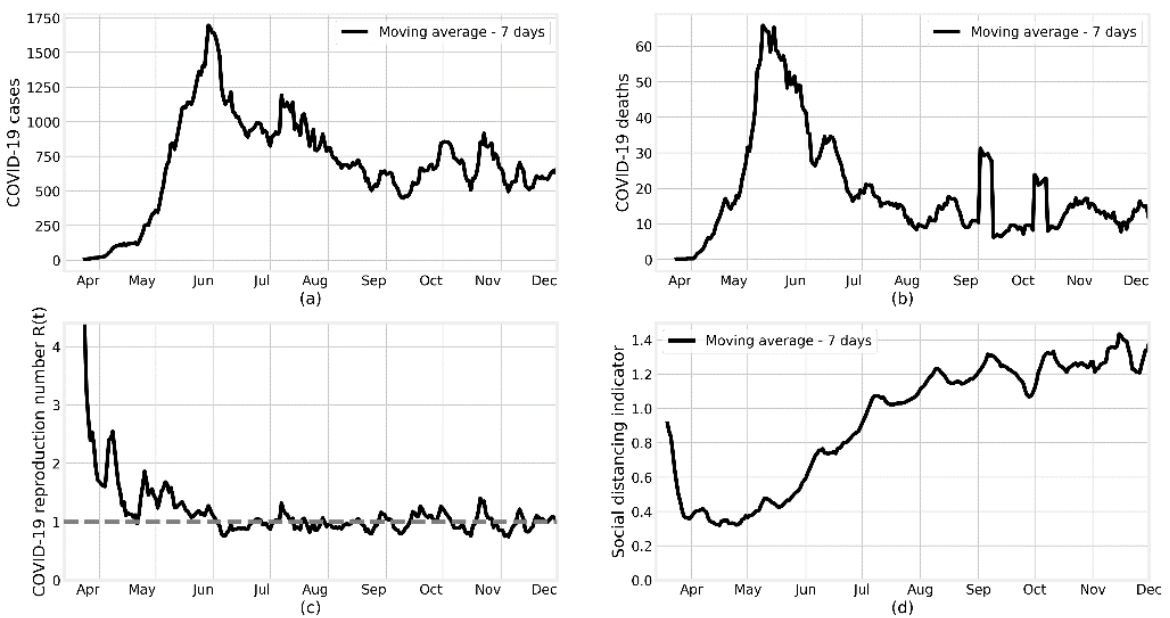

Figure 1. Key COVID-19 trend data and social distancing indicator data for the State of Amazonas

Figure 1 presents key COVID-19 trend data for the State of Amazonas based on 7-day moving averages from 13 March to 01 December 2020. Numbers for coronavirus cases and deaths were sourced from Brasil.io, a Brazilian initiative to aggregate public health data. Reproduction rates were calculated as per Thompson et al. (2019). The social distancing indicator is a composition of six Google Community Mobility Report indicators and is constructed as per de Oliveira et al. (2020). According to Poletti et al. (2012) "human responsiveness is more effective when disease symptomaticity is larger." The Google data for the initial phase, February to April, is consistent with extant evidence that states with more COVID-19 cases present better social distancing indexes (GNN, 2020), suggesting that as COVID-19 becomes more prevalent in an area, the population tends to stay home, leaving only for essential activities. As can be seen, after an initial positive response to social distancing and social isolation interventions from February to April, there was a decline from mid-April to June, potentially from so-called "pandemic fatigue" (or "lockdown fatigue") or perceived or actual relaxation of social distancing by the Government. As cases and deaths increased, social distancing once again increases. While the reproduction number $(\mathrm{R})$ declined after the initial peak, it stays around 1 suggesting that the infection continued to grow throughout the year, as evidenced in the rise in cases and deaths. This is consistent with other reported analysis which included data from the State of Amazonas (Mellan et al. 2020; Petherick et al. 2020). However, given the $\mathrm{R}$ number, and number of cases and deaths, the data suggests greater social distancing adherence is needed to curb the spread of disease.

In order to get better insights in to movement activity, mobility data by place was analysed. Figure 2 presents mobility data for Amazonas from 15 February to 01 December 2020, categorized by Google-defined places. There is a clear trend towards increased activity at residential places (internal) and decreased activity at external places (shopping, workplaces etc.) following initial state interventions. From April onwards, the social distancing indicator decreased and stabilized at values close to the baseline (pre-pandemic), mainly from August, as the economy reopened. The State of Amazonas was the first Brazilian state to recommence classes in public schools. Elementary classes, scheduled to start on August 24, were postponed to September 30 in a hybrid teaching format (Beatriz, 2020). As both cases and deaths began to rise again in September, parents responded negatively to Government policies requiring on-site school attendance resulting in protests (Beatriz, 2020). Figure 2 also shows the growing trend in circulation at workplaces, supermarkets, pharmacies and transit places. Similarly, as public spaces, such as parks and beaches, reopened in mid-August, movement in this category increased dramatically. Increased circulation peaked around the Brazilian Independence Day holiday in early September. By 24 September, increases in cases, hospitalization, and deaths resulted in a Due to the increase in the number of cases and the occupation of hospital beds, on September 24 the State Government closed public spaces again for a period of 30 days, again reflected in the Google data in Figure 2. Again, this analysis suggests the Google Community Report Data has good explanatory value for Coronavirus trends and highlights a need for policy interventions at not only government-controlled places, e.g. transit points and public places, but also at workplaces if the disease is to be controlled. 


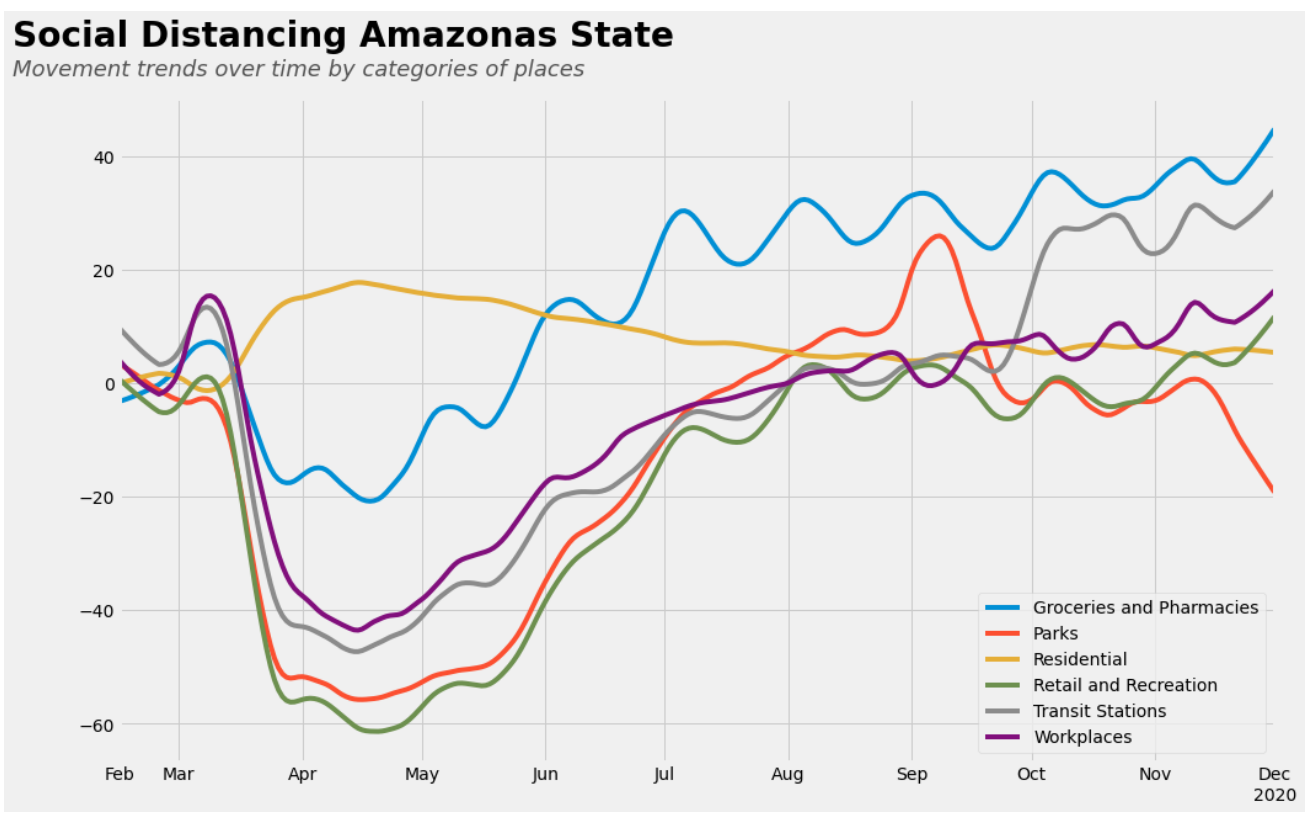

Figure 2. Social distancing trends by category type for Amazonas based on Google Mobile Community Reports

Figure 3 compares the states in the Northern Region of Brazil and Brazil as a whole. For the period from February to May 2020, Amazonas was the only state that reached the national average for social distancing; only the states of Amapá and Pará exceeded the national average. There is a sudden drop and recovery in the trend data for the State of Amapá at the beginning of November. The State faced a series of power blackouts caused by a fire that impacted most of the population. This resulted in electricity rationing in the electricity supply for that period impacting telecommunications service provision. This suggests that social distancing is a widespread problem and both adherence and enforcement has not been stringent enough.

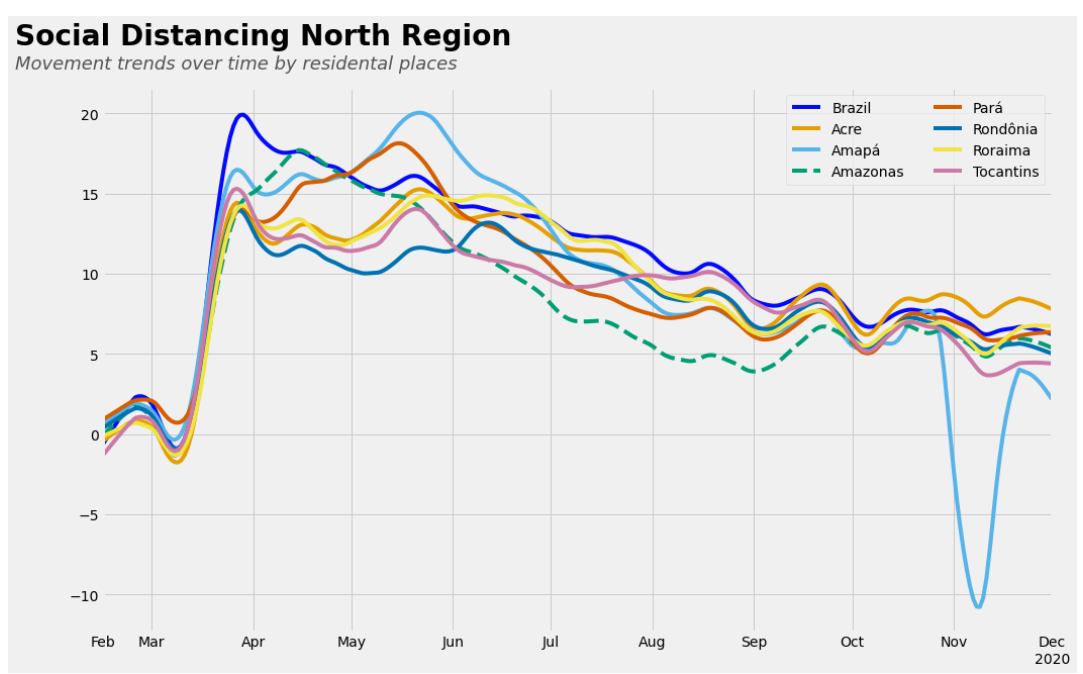

Figure 3. Social distancing trends by based on residential place for Brazil and the Northern Region States of Brazil based on Google Mobile Community Reports

To understand differences in policy responses between Amazonas and Brazil as a whole, we use data from the Oxford COVID-19 Government Response Tracker project (OxCGRT) (Hale et al. 2020) to compare the State of Amazonas, the largest city in Amazonas, Manaus, and Brazil. Figure 4 suggests that after a period of more stringent policies and intervention at the State level, this declined to similar levels as Manaus, its capital 
city, and ultimately lower levels than Brazil. This data is insightful as it suggests that lower stringency in Manaus, which accounts for nearly two thirds of the population of the State of Amazonas, could explain the overall performance of the State. It also indicates the need for more local interventions.

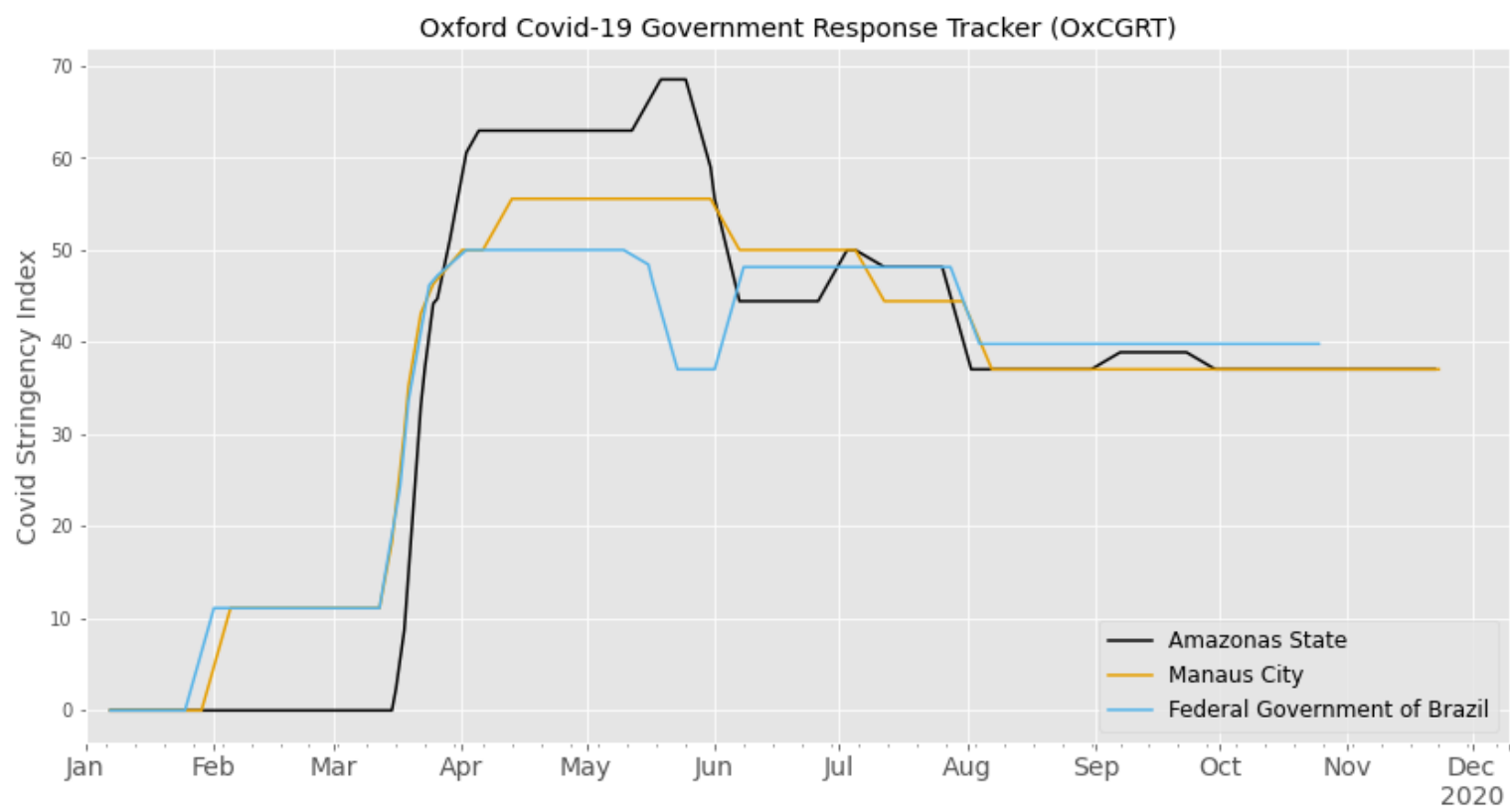

Figure 4. Comparison of the COVID Stringency Index for the State of Amazonas, Manaus and the Brazil

\section{DISCUSSION AND CONCLUSION}

This paper explored the utility of Google Community Mobility Report data for evaluating the efficacy of social distancing and related public health interventions in the largest state in Brazil, Amazonas. We find that such data can provide a simple, rapid, low cost, time- and context sensitive indicator for evaluating the efficacy of intervention strategies such as social distancing. Results suggest that while the public health interventions in Amazonas had some initial and ongoing success in reducing the spread of COVID-19, the absence of a sustained strict lockdown meant that the overall impact was limited. The decline in adherence is often attributed to lockdown or pandemic fatigue, a term Michie et al. (2020) recently noted in itself is ambiguous. A better understanding of levels of adherence and determinants of declining adherence would inform public health decision making however it is a complex area and includes not only mental or physical tiredness and distress from prolonged exposure to an aversive set of circumstances, both forms of fatigue, but other non-fatigue related factors including concern related to life circumstances, confusion about public health communications, and lack of trust in Government (Michie et al. 2020). It may also be related to demongraphics and cultural context. In this regard, mobile data may provide some additional insights. Our analysis suggests that policymakers that in the context of Amazonas and in the absence of a widespread vaccination programme and herd immunity, more stringent interventions and enforcement of adherence to social distancing is required in the State of Amazonas if COVID-19 is to be controlled and the R number brought below 1. Furthermore, the data, when analysed by place, suggests that it is not only important to control movement in the state-controlled locations and the public realm, but to limit travel and interaction in workplaces, retail and other places of recreation, in effect a total lockdown. Our comparison of trend data for the Northern Region of Brazil and Brazil as a whole suggests this is a widespread problem in Brazil and is consistent with other studies using different methodologies (Mellan et al. 2020; Petherick et al. 2020). 
Our preliminary analysis reconfirms previous literature that in the absence of mobility data from official sources, anonymous mobile phone traces can be used as a proxy of human movement and social interactions (Tizzoni et al. 2014; Oliver et al. 2020). In addition to Google Community Mobility Reports, recent studies suggest spatio-temporal data from other mobile applications, not designed for public health purposes, can be useful for monitoring adherence to public health policies in pandemics (Endo et al. 2020). However, this requires changes in "digital mindset" and capabilities from governments and public authorities, and mechanisms to access data from commercial sources while addressing concerns about data privacy, data protection and civil liberties (Oliver et al. 2020). The former requires a significant investment in digital capacity building in the public sector, while the latter requires multi-stakeholder dialogue between the public sector, private enterprise, data protection authorities, and civic society on (i) the trigger events that might mandate access to such data, and (ii) and data governance needed to minimise the use of such data.

From a research perspective, this paper represents an exploratory data analysis. It requires further sensitivity analysis and validation. Notwithstanding the significant correlations between the Google Community Report Data and public health interventions, this data should be relied on with caution. Amazonas, and Northern Brazil generally, suffers from mobile infrastructure limitations, resulting in incomplete coverage, intermittent connectivity, and less accurate data. It is source from a sub-sample of mobile users. Consequently, it is not representative of the population in Amazonas or northern states, all of whom report poverty indicators above the national average (IBGE, 2019). Given that many at risk populations live in poverty or in rural areas, reliance on such data for policy decisions may neglect the most vulnerable in Brazilian society, who may neither have a mobile phone nor easy access to treatment.

\section{REFERENCES}

Beatriz, R., 2020. Asprom Sindical installs teachers' strike against return of classes in the AM. https://g1.globo.com/am/amazonas/noticia/2020/08/10/asprom-sindical-instala-greve-dos-professores-contra-retornodas-aulas-no-am.ghtml

Buss, L.F., Prete, C.A., Abrahim, C.M., Mendrone, A., Salomon, T., de Almeida-Neto, C., França, R.F., Belotti, M.C., Carvalho, M.P., Costa, A.G. and Crispim, M.A., 2020. Three-quarters attack rate of SARS-CoV-2 in the Brazilian Amazon during a largely unmitigated epidemic. Science.

Charaudeau, S., Pakdaman, K. and Boëlle, P.Y., 2014. Commuter mobility and the spread of infectious diseases: application to influenza in France. PloS one, 9(1), p.e83002.

de Oliveira, GLA, de Lima, LC, Silva, I., Ribeiro-Dantas, MDC, Monteiro, KH and Endo, PT, 2020. Measures of social distance and mobility in South America during the pandemic by COVID- 19: Necessary and sufficient conditions ?. arXiv preprint arXiv: 2006.04985 .

Endo, P.T., Silva, I., Lima, L., Bezerra, L., Gomes, R., Ribeiro-Dantas, M., Alves, G., Monteiro, K.H.D.C., Lynn, T. and Sampaio, V.D.S., 2020. \# StayHome: Monitoring and benchmarking social isolation trends in Caruaru and the Região Metropolitana do Recife during the COVID-19 pandemic. Revista da Sociedade Brasileira de Medicina Tropical, 53.

Estado do Amazonas, 2020. Poder Executivo - Seção I. http://www.amazonas.am.gov.br/content/uploads/2020/05/poder_executivo_SECAO_I_28-05-2020.pdf

FVS (Fundação de Vigilância em Saúde do Amazonas), 2019. http://www.fvs.am.gov.br/

G1, 2020. Governo admite insuficiência de leitos no sistema de saúde do AM mesmo antes da pandemia de Covid-19. Available: https:/g1.globo.com/am/amazonas/noticia/2020/04/16/governo-admite-insuficiencia-de-leitos-no-sistemade-saude-do-am-mesmo-antes-da-pandemia-de-covid-19.ghtml

Google, 2020. Google COVID-19 Community Mobility Reports. Available: https:/www.google.com/covid19/mobility/

GNN, 2020. Tendência de isolamento social desacelera no Brasil. Available: https://jornalggn.com.br/a-grandecrise/tendencia-de-isolamento-social-desacelera-no-brasil/

Hale, T., Webster, S., Petherick, A., Phillips, T. and Kira, B., 2020. Oxford COVID-19 government response tracker. Blavatnik School of Government, 25.

IBGE, 2019. Extreme poverty affects 13.5 million persons and hits highest level in seven years. Available: https://agenciadenoticias.ibge.gov.br/en/agencia-news/2184-news-agency/news/25895-extreme-poverty-affects-13-5million-persons-and-hits-highest-level-in-seven-years

Michie, S., West, R. and Harvey, N., 2020. The concept of "fatigue" in tackling covid-19. BMJ, 371. 
Oliver, N., Letouzé, E., Sterly, H., Delataille, S., De Nadai, M., Lepri, B., Lambiotte, R., Benjamins, R., Cattuto, C., Colizza, V. and de Cordes, N., 2020. Mobile phone data and COVID-19: Missing an opportunity? arXiv preprint arXiv:2003.12347.

Orellana, JDY, Cunha, GMD, Marrero, L., Horta, BL and Leite, IDC, 2020. Explosion of mortality in the Amazonian epicenter of the COVID-19 epidemic. Cadernos de Saúde Pública, 36, p.e00120020.

Poletti, P., Ajelli, M. and Merler, S., 2012. Risk perception and effectiveness of uncoordinated behavioral responses in an emerging epidemic. Mathematical Biosciences, 238(2), pp.80-89.

Thompson, R.N., Stockwin, J.E., van Gaalen, R.D., Polonsky, J.A., Kamvar, Z.N., Demarsh, P.A., Dahlqwist, E., Li, S., Miguel, E., Jombart, T. and Lessler, J., 2019. Improved inference of time-varying reproduction numbers during infectious disease outbreaks. Epidemics, 29, p.100356.

Tizzoni, M., Bajardi, P., Decuyper, A., King, G.K.K., Schneider, C.M., Blondel, V., Smoreda, Z., González, M.C. and Colizza, V., 2014. On the use of human mobility proxies for modeling epidemics. PLoS Comput Biol, 10(7), p.e1003716. 